\title{
Editorial
}

\section{La tragedia social de El Salvador}

Hasta hace poco, sólo unas cuantas voces -incluidas las de la UCA y en particular la de $E C A$ - que, por cierto, sonaban fuera de lugar, habían advertido sobre el deterioro generalizado de la vida social salvadoreña. El gobierno y los medios de comunicación de masas se habían propuesto imponer la imagen de un país que avanzaba, lenta, pero de manera segura, hacia un futuro promisorio de prosperidad y bienestar. Con contadas excepciones, el convencimiento de que la transición conducía a El Salvador a puerto seguro, con independencia de la trayectoria de su curso, era incuestionable. Pero, en unas pocas semanas, este convencimiento se resquebrajó y dejó ver la tragedia social de esa transición —en apariencia exitosa-.

El detonante fue doble - la constatación de que en la Policía Nacional Civil había bandas de delincuentes y la acumulación de secuestros, algunos de los cuales son atribuidos a estas bandas de policías--, pero para el observador acucioso - y no ideologizado-, las señales eran inconfundibles, desde hacía mucho tiempo. Vivir es tan difícil en El Salvador que sus habitantes lo abandonan. En realidad, lo vienen haciendo desde hace dos décadas. La cuestión es que para estos miles de emigrantes, la transición promete menos que los riesgos que comportan abandonar la tierra natal y buscar esa prosperidad y ese bienestar en otro país. La población ha perdido la confianza en aquellos que debieran ayudarla a vivir; no cree que El Salvador sea un país nuevo como para permanecer en él. Al contrario, percibe que sus libertades fundamentales — a la igualdad, a un nivel de vida digno, a la seguridad, a desarrollar su potencial humano, a la justicia, a la parricipación, expresión y asociación y a un trabajo digno- le son negadas y, por lo tanto, sus derechos básicos le son violados de manera sistemática.

En esta actitud hay mucho de desencanto y escepticismo, surgidos de la comprobación de que la vida no es viable en El Salvador. Su tragedia consiste en que perdió su unidad social básica desde finales de los setenta y, hoy, casi una década después de concluida la guerra civil, la sociedad salvadoreña 
no ha podido encontrar aún los elementos claves para reconstituir esa unidad elemental pérdida, de tal manera que su reproducción no se vea en peligro.

\section{La pérdida de la unidad social básica}

La unidad de la sociedad salvadoreña no desapareció de manera repentina, sino que su desarticulación es resultado de un largo proceso histórico, impulsado por tendencias de larga data. Sin embargo, el proceso de disolución, en lugar de ser detenido y rectificado, fue acelerado por las decisiones de los gobiernos de ARENA. Esto no quiere decir tampoco que con anterioridad a éstos e incluso que antes de la guerra civil, la estructura social salvadoreña mostrara una solidez tal que la vida humana se desarrollara en su seno de una manera equitativa, justa y libre. Sin embargo, en aquel entonces e incluso durante la guerra civil, la configuración de la sociedad mostraba una articulación que ahora, a comienzos del siglo XXI, se echa en falta. La guerra civil fue consecuencia de las primeras fracturas, producidas al agotarse las posibilidades del desarrollismo y del mercado común centroamericano. La guerra profundizó esas fracturas, debilitando aún más la estructura social. Poco contribuye a recuperar esa articulación social fundamental una política gubernamental, de la cual los medios de comunicación de masas se hacen eco, orientada a exacerbar la libertad individual como consecuencia aparentemente inevitable del establecimiento de un mercado, el cual todavía se ilusiona con llegar a ser libre, pero que aún no se ha podido liberar de la competencia desleal, de los monopolios, de los oligopolios, de las relaciones informales, ni de todas las normas y regulaciones.

La sociedad salvadoreña se ha ido deshaciendo de una manera gradual e inexorable, hasta llegar a una desarticulación y destrucción tales que no pueden seguir siendo desconocidas. Este extremo de desvalorización de la vida y de lo humano es el que ha hecho saltar la tragedia salvadoreña a primer plano. La cuestión no es desconocer o resistir los cambios que todo proceso histórico deja, sino que los cambios ocurridos, y en gran medida evitables, han llevado a la desarticulación de la sociedad salvadoreña y, por consiguiente, han puesto en grave peligro su reproducción.

No obstante, una mezcla de ingenuidad y credulidad ha llevado a quienes tienen el poder para dictar la política nacional a creer a pie juntillas que la libertad, entendida como ausencia de leyes, normas y referentes, es el valor más genuino de la naturaleza humana. Las consecuencias de esta creencia están a la vista: libertad de unos pocos a costa de la opresión de la mayoría y libertad de quienes tienen fuerza para imponer su voluntad sobre los que no disponen de ella. Una libertad que descansa en la exclusión de la mayoría y se apoya en la fuerza de la minoría es una quimera. Sin embargo, es una quimera con consecuencias graves. La libertad así entendida nunca ha existido en la historia de la humanidad. Son las sociedades las que organizan la 


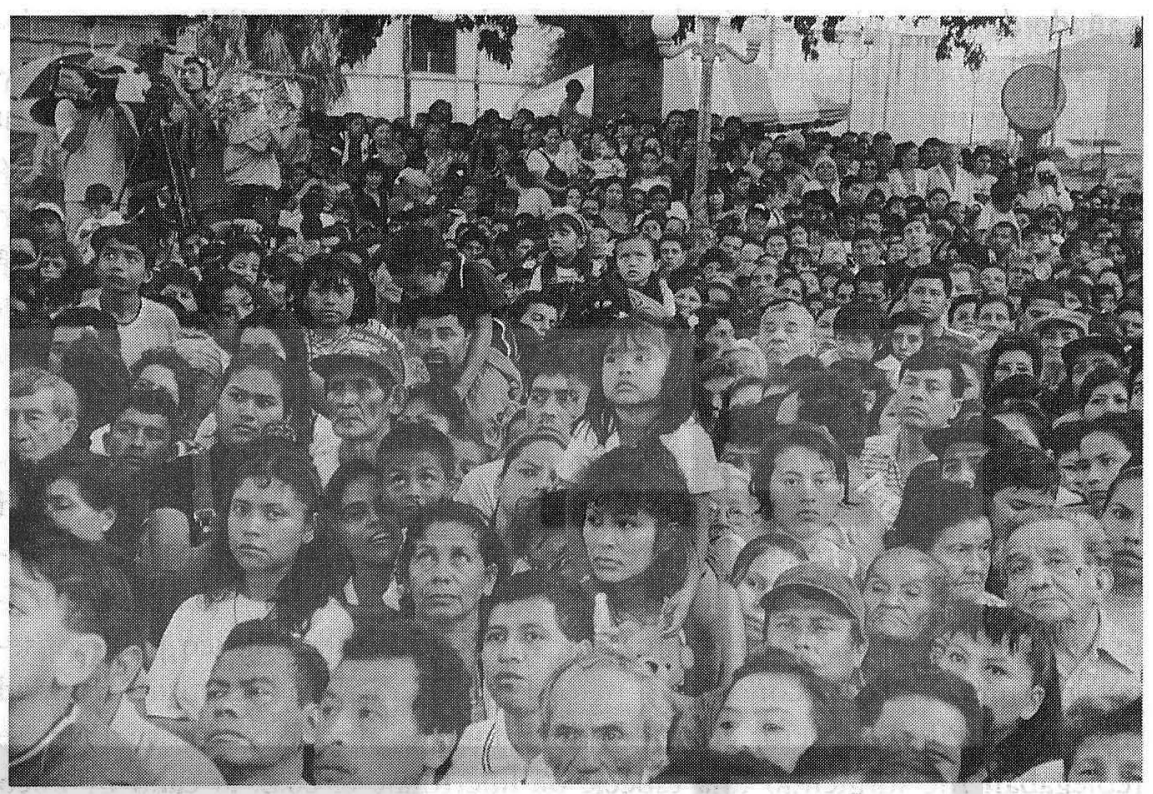

vida individual y colectiva, imponiendo costumbres, reglas y leyes, más o menos orientadas a garantizar cierta igualdad y seguridad. En el caso salvadoreño es difícil preçisar cuánto de la disolución actual es atribuible a la guerra civil y cuánto a la política de desregulación de la posguerra, no sólo del mercado, sino también de la sociedad. Lo que sí es evidente es que de la estructura social de la década de los setenta, cuya consistencia es cuestionable, queda poco a comienzos del nuevo siglo. El vacío dejado por su desaparición ha sido llenado por un darwinismo social cada vez más mortal.

Los datos que respaldan esta percepción generalizada en la sociedad salvadoreña son abundantes y comprenden todos los ámbitos de su vida. Lo que más impacta a la conciencia colectiva son las diversas manifestaciones de la violencia. El efecto acumulado de asesinatos, secuestros, asaltos, delincuencia común, violencia juvenil y agresiones diversas contra los sectores sociales más vulnerables - mujeres, niños, ancianos y grupos minoritarios-, lleva a creer que la violencia es mayor de lo que en realidad es y refuerza la percepción de inseguridad. La comprobación de la existencia de bandas organizadas de delincuentes dentro de la Policía Nacional Civil, además de explicar parcialmente la impunidad, alimenta la sensación de incertidumbre y descontrol. Casi a la par de la violencia, pero en un segundo plano, se encuentra el deterioro creciente de la economía de la mayoría de las familias salvadoreñas. Sin embargo, la presión que empuja hacia la línea de la pobreza es sentida con mayor intensidad por la clase media profesional. El deterioro paulatino, pero constante, de las condiciones de vida de esa mayoría implica, por el otro lado, el aumento desmesurado de la riqueza de un pequeño grupo, el cual se enriquece a costa de la pobreza de los demás. El empobrecimiento va acom- 
pañado de desempleo, salarios bajos, ausencia de servicios públicos para quienes más los necesitan y aumento de la incidencia de las enfermedades relacionadas con la pobreza - siendo el dengue hemorrágico la última en hacer su aparición, la cual, para colmo de males, se ha cebado en la niñez. No deja de ser paradójico que una población que tiene una fama bien ganada de ser disciplinada y diligente no pueda superar la línea de la pobreza; al contrario, la fuerza que la empuja hacia abajo no sólo no cede por más esfuerzo que ella oponga, sino que también está arrastrando consigo a una clase media no muy grande, pero hasta hace muy poco, bastante segura de sí misma y de su futuro.

A estas inseguridades e incertidumbres contribuye de una manera determinante y no debidamente apreciada la debilidad institucional de la sociedad y del Estado salvadoreños. La derecha asumió sin mayor crítica que la intervención estatal era contraria al desarrollo económico y social, y, por consiguiente, se empeñó en reducirla al mínimo. Urilizó el poder político para conseguir sus propios fines económicos, pero al hacerlo debilitó la institucionalidad social y estatal en aspectos cruciales. En la medida en que las instituciones se replegaban fue surgiendo una especie de libertinaje el cual, al cabo de poco tiempo, se ha convertido en el comportamiento ordinario. Los teóricos estadounidenses del mercado libre, en cambio, sostienen que antes de privatizar los servicios públicos es necesario crear las instituciones encargadas de supervisarlos en su nueva modalidad; pero sus seguidores salvadoreños hicieron lo contrario. El resultado es que tales servicios están dejando de ser públicos y sólo son accesibles para quienes pueden pagar por ellos, porque se han convertido en un medio de lucro sin que haya instituciones sólidas con la fuerza necesaria para controlarlos. Los responsables de la privatización todavía no han caído en la cuenta de lo que han hecho, aunque sí de sus consecuencias. Ellos también viven en la inseguridad y la incertidumbre, pero en lugar de rectificar, insisten aún en mantener la misma política neoliberal. Reclaman la pérdida de valores y exigen retornar a ellos, sin caer en la cuenta que nadie como ellos ha transformado la realidad social y lo ha hecho de una manera tan radical que toda vuelta atrás es, en la práctica, imposible. Añoran el pasado, pero no están dispuestos a renunciar al presente. En su añoranza son conservadores, pero en las transformaciones que impulsan son radicales.

[La población] no cree que El Salvador sea un país nuevo como para permanecer en él. Al contrario,

percibe que sus libertades fundamentales - a la igualdad,

a un nivel de vida digno, a la seguridad, a desarrollar

su potencial humano, a la justicia, a la participación, expresión

y asociación y a un trabajo digno- le son negadas y, por lo tanto,

sus derechos básicos le son violados de manera sistemática. 
En contradicción abierta con su credo liberal, el radical de derecha reacciona ante la incertidumbre y la inseguridad legislando, cuando lo que hace falta es la institución que aplique la ley existente e imponga la sanción establecida. El ciudadano, al igual que el funcionario, se muestra indiferente ante la ley, porque está convencido de que su respeto o cumplimiento no le será exigido y, si lo fuera, existen modos para evadir la sanción social y judicial. Es así como la permisividad predomina en casi todos los ámbitos de la vida individual y social. Es una permisividad que no conoce otro límite que la fuerza que pueda oponerle el otro; por lo tanto, no reconoce prohibiciones de ninguna clase. En parte, esta permisividad, de la cual nos quejamos cuando somos víctimas, pero a la cual contribuimos al actuar en contra de las normas y costumbres establecidas, se explica por la indiferencia y la venalidad del sistema judicial y, en parte, por la ausencia de referentes ciudadanos y sociales. Lo que queda de la institucionalidad estatal y los funcionarios mismos no son creíbles. El mensaje de las iglesias, por ejemplo, aunque escuchado con gusto, sobre todo cuando adquiere un tono paternalista, no influencia la conducta personal y comunitaria; al menos no en la medida en que la situación de disolución social y personal lo reclama.

El resultado de esta manera de vivir, por un lado, impuesta desde arriba; pero, por el otro lado, aceptada y reproducida por decisión individual, en orden a satisfacer toda clase de egoísmos, es la disolución de los vínculos y las responsabilidades familiares, comunitarias y sociales. El predominio de lo individual con menoscabo del bien común ha convertido las relaciones personales y sociales en objeto de intercambio o negociación y, por consiguiente, en provisionales y revocables. La solidaridad, la comprensión y el cariño familiar son effímeros e interesados, puesto que se encuentran a merced de los caprichos y las apetencias individuales. Las uniones conyugales no presuponen la fidelidad, ni la durabilidad. El hogar es uno de los sitios donde más violencia se ejerce contra la mujer, los niños y los ancianos; paradójicamente, es uno de los lugares más inseguros para los miembros más vulnerables del grupo familiar, quienes se encuentran abandonados a los apetitos sexuales incontrolados de los adultos. El conflicto intrafamiliar y la ausencia de adultos en el hogar lanzan a los niños al vecindario o, peor aún, a la calle, exponiéndolos a peligros innecesarios. En los hogares por debajo de la línea de la pobreza, los niños y las niñas son obligados a trabajar o a hacer de la calle su morada desde muy temprana edad.

No sólo las relaciones sociales elementales se resquebrajan con bastante facilidad y en poco tiempo, sino que también el espacio urbano se encuentra fragmentado. Grupos urbanos enteros se aíslan del resto de la comunidad y se encierran, levantando muros y barreras, colocando dispositivos electrónicos y guardias, cuyo propósito es controlar y restringir. Entre más elevado el ingreso del grupo familiar, la vida de sus miembros está más sometida a esta clase de controles y restricciones. Estas opciones que, evidentemente, atentan 
contra la unidad social básica, se han ido introduciendo de manera gradual hasta convertirse en algo normal.

Este diagnóstico desolador de la sociedad salvadoreña sugiere hacer una analogía con la droga y la drogadicción: la sociedad salvadoreña se ha vuelto adicta a "la droga social" y, por lo general, vive "drogada". La necesidad de mantener ese estado de "drogadicción" la lleva a consumir más "droga". Es así como aquélla ha quedado atrapada en "un círculo vicioso" del cual sólo podrá ser liberada por la muerte o por "una terapia social" larga y difícil.

\section{La tendencia a idealizar el pasado}

Este panorama no pretende ser completo, sino sólo señalar aquellos aspectos más importantes de la sociedad salvadoreña actual, en los cuales descansa la percepción, por otra parte, real, de que algo importante se ha perdido. Se puso fin a la guerra civil, pero la paz y el bienestar social no llegaron; se concluyó la transición de posguerra, pero no se avanzó gran cosa en la democratización. $Y$, en el intervalo, con el pretexto de la modernización, se desataron las fuerzas de un capitalismo que después no han podido ser contenidas, ni controladas; pero que en lugar de prosperidad y bienestar, está dejando destrucción y muerte a su paso. Esto es lo que da pie para afirmar que algo muy importante se ha perdido a lo largo del proceso de la transición de posguerra.

Entonces es cuando se tiende a idealizar el pasado, olvidando que éste estaba configurado de una manera tal que desembocó en una guerra civil cruel y sangrienta. La desconcertante realidad social actual suele ser atribuida a una pérdida de valores, cuya vigencia en el pasado reciente se da por supuesta - lo cual es muy discutible. Por eso, se enfatiza su rescate, asumiendo a priori que, si se logra, el desorden predominante desaparecería. Es una formulación revisada de la vieja creencia de que todo pasado fue mejor. Estos reclamos son más insistentes por el lado de la derecha, a la cual le gusta imaginar que es la voz del pasado; pero la realidad es muy distinta. La derecha salvadoreńa mira el pasado con enorme desconfianza, porque se sabe responsable de la guerra civil y sus consecuencias. De ahí su insistencia en olvidarlo y quienes se lo recuerdan, la irritan sobremanera. Asimismo, desconoce que la radicalidad de las transformaciones que ha introducido en la realidad salvadoreña durante la última década, la atan sin remedio al caos actual, sobre el cual, como es obvio, tampoco puede aceptar responsabilidad alguna. Entonces, no le queda más alternativa que el futuro, del cual se apodera, creyendo, con más o menos convicción, que la productividad creciente resolverá por sí misma la mayor parte de los problemas sociales. Este optimismo de la derecha sólo puede ser calificado como salvaje, puesto que sus costos sociales son elevados, carece de respaldo teórico y práctico y los riesgos en los cuales está colocando a la sociedad salvadoreña son muy peligrosos. No obstante, no se puede pasar por alto el éxito conseguido por esta derecha, al trasladar su visión de las cosas a la sociedad. 
La nostalgia por ese pasado idealizado no sólo lamenta no haber alcanzado las metas esperadas de la guerra civil y la transición, sino también haber perdido una realidad que le era familiar y querida - independientemente de las críticas que se pudieran hacer. La realidad que ha arrojado la transición no sólo no responde a sus expectativas - lo más probable es que ni siquiera responda a las de sus propios diseñadores y ejecutores-, sino que tampoco está abriendo a un futuro que devuelva, de alguna manera, algo de lo perdido. En este sentido, se tiene cada vez más la percepción de que la pérdida es irreversible e irreparable y, dado que lo existente es a todas luces insatisfactorio, de él no se puede esperar un futuro mejor, tal como la derecha sueña.

Las políticas adoptadas hasta ahora para rescatar y, o impedir que las formas tradicionales de vida familiar y social salvadoreńa continúen desapareciendo, así como para reprimir las manifestaciones peores de la delincuencia no han arrojado los resultados esperados. La derecha se autoengaña al creer que una polírica de ley y orden es el sustituto adecuado de las instituciones sociales y estatales, que el mercado libre ha echado por la borda. El estado actual de descontrol y anarquía social y las posibilidades, en la práctica nulas, de que el futuro pueda dar paso a un orden nuevo, fundamentado en una mayor equidad y bienestar, es ocultado cuidadosamente por la cooptación del discurso. En todas partes, la razón de ser de los gobiernos es garantizar la vida, la seguridad y la prosperidad de sus ciudadanos. Por lo tanto, un gobierno que no pueda cumplir con esta triple función esencial, lo único que hace es crear las condiciones para la inestabilidad. Cuando no se posee una alternativa viable, lo único que queda es ganar tiempo para retrasar lo que de antemano se sabe inevitable. Los mismos que han dictado e

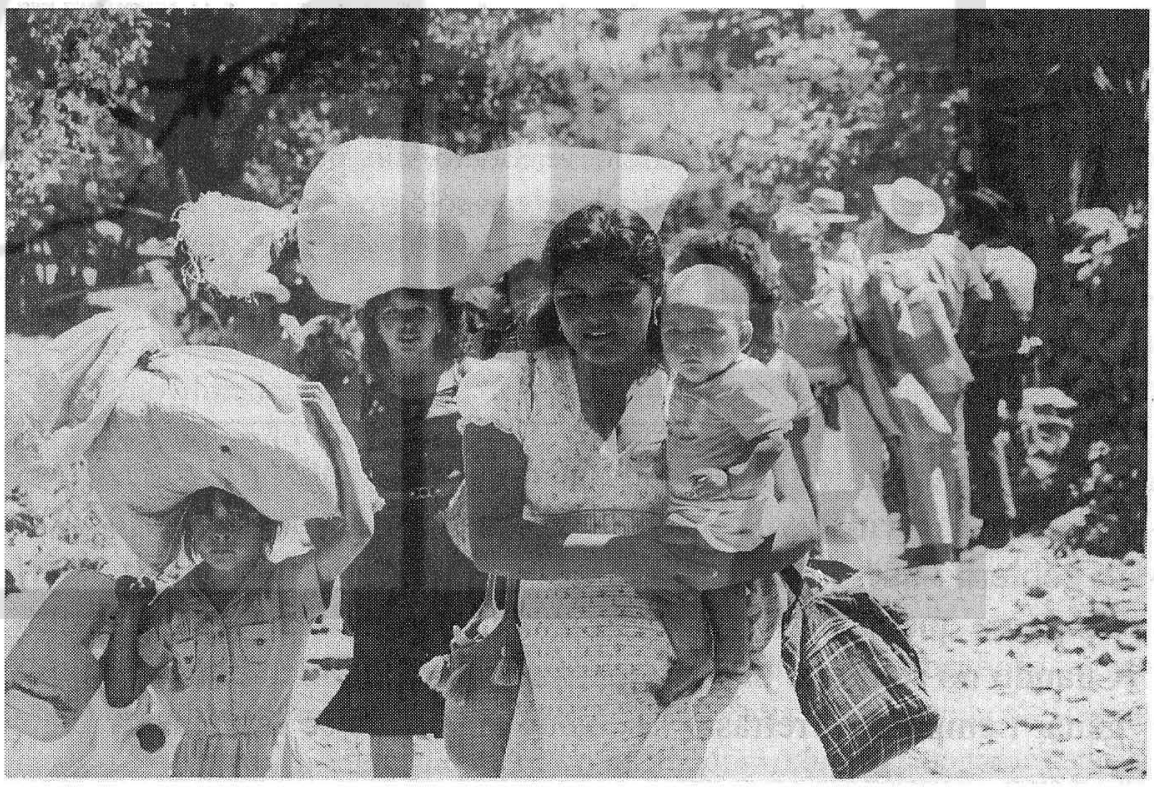


impuesto las políticas económicas que han llevado a El Salvador a su situación actual son los que también se han apropiado de conceptos como cambio, prosperidad y bienestar social, novedad e innovación, futuro mejor, etc.; pero vaciándolos de contenido. El cambio y la novedad vendrían dados por los resultados de sus políticas, la prosperidad y el bienestar se harían realidad gracias a un crecimiento que creen indefinido e ilimitado, y, en consecuencia, el futuro que anuncian será similar al presente que han creado. Incluso se atreven a hablar de la pobreza y de los pobres y de su compromiso para hacer desaparecer a ambas.

La apropiación de la terminología del cambio social, incluyendo la problemática de la pobreza, no ha proporcionado, sin embargo, la credibilidad que el régimen quizás buscaba; pero sí le ha sido de utilidad para desmovilizar, al menos por el momento, a las mayorías empobrecidas y a la clase media profesional descontentas, y así ganar tiempo -y tal vez incluso tranquilizar su mala conciencia. De esta manera, el poder establecido ha conseguido despojar a las palabras de su poder de convocatoria, de tal modo que éstas ya no evocan los ideales revolucionarios del pasado, ni utopías por las cuales luchar en el presente para construir un futuro más humano y justo. No debe extrañar, entonces, que el lenguaje - y no pocas veces las actitudes ante la realidad social- de la izquierda, revolucionaria o urópica, y el de la derecha capitalista y antidemocrática sea muy similar. La derecha se ha apropiado del discurso del cambio social para justificar las transformaciones que ha impulsado, equiparando de manera artificiosa y falaz cambio con prosperidad y bienestar generales. La izquierda, por otro lado, cautelosa para no aparecer como contraria a la democracia, ni al mercado libre y amenazada desde dentro por la división, originada en la ambición de poder y dinero de algunos de sus dirigentes, no ha podido retener el poder subversivo de la palabra. Paradójicamente, estos equilibrios de la derecha y la izquierda también han abierto espacio para que cualquiera pueda utilizar en la actualidad estos conceptos, incluso atribuyéndoles su contenido verdadero, sin por ello provocar una conmoción social, tal como sucedía hace tan sólo una década. En la actualidad, son contadas las instituciones y personas cuya palabra tiene poder. A ellas les corresponde, sin embargo, esforzarse por decir la verdad y señalar las utopías que den sentido a la vida social y personal.

... la razón de ser de los gobiernos es garantizar la vida, la seguridad y la prosperidad de sus ciudadanos [...]

un gobierno que no pueda cumplir con esta triple función esencial, lo único que hace es crear las condiciones para la inestabilidad.

Cuando no se posee una alternativa viable, lo único que queda es ganar tiempo para retrasar lo que de antemano se sabe inevitable. 
Ahora bien, no cualquiera tiene acceso a estos espacios para enjuiciar la realidad y participar en el debate público. La voz popular es mediatizada o silenciada por los grandes medios de comunicación de masas. Los espacios no son, pues, tan libres como parece a primera vista. Las pocas voces disonantes que se dejan escuchar son toleradas porque no representan amenaza alguna para quienes detentan el poder -económico, polírico, social, jurídico y religioso. Esto es posible por la imposición de un poder oligárquico sobre la sociedad y continuará siendo así hasta que las mayorías populares no recuperen su libertad de expresión, se apoderen del poder de la palabra y expresen sus juicios sobre la realidad actual y su futuro con claridad y determinación. La liberación de la palabra es necesaria para no caer en la idealización del pasado, el desconocimiento del presente y en la huida hacia delante.

\section{La huida de la dura realidad}

La reacción de la mayor parte de los salvadoreños es, sin embargo, desconcertante, puesto que éstos no se muestran inclinados a luchar para hacerse oír por aquellos que tienen el poder en sus manos y toman las decisiones políticas. Es indudable que El Salvador ha llegado a esta situación crítica (ver el editorial "La seguridad en crisis", ECA 619-620, mayo-junio de 2000, pp. 493ss.) porque la sociedad lo ha permitido con su tolerancia —o tal vez sería más apropiado decir permisividad. En todo caso, esta actitud hace que algunos caigan en el equívoco de que la población salvadoreńa no puede relacionar la política gubernamental con sus efectos negativos, los cuales ella experimenta de modo directo y continuo y, por lo tanto, no puede explicarse racionalmente lo que le sucede. De ahí que no sólo no actúe para evitarlo, sino que incluso continúe votando por ARENA, el responsable principal de esa política.

La tolerancia salvadoreña contrasta, a primera vista, con la reacción agresiva de otras sociedades centroamericanas, la guatemalteca, por ejemplo, que no permite al gobierno elevar el precio del transporte público y que, ajena ancestralmente a las disposiciones de la legislación vigente, se toma la justicia por su propia mano con tranquilidad pasmosa, en las zonas rurales e indígenas, o la costarricense, que impidió al Presidente de la República la rarificación de una ley destinada a privatizar bienes y servicios públicos. En ambos casos, movilizaciones masivas, más violentas en Guatemala que en Costa Rica, han obligado a los gobiernos respectivos a dar marcha atrás. En cambio, a la sociedad salvadoreña ninguna arbitrariedad, injusticia o escándalo -ampliación del impuesto al valor agregado, subida descontrolada del precio de los combustibles, escasez de gas y agua, descontrol de la violencia y del delito, arbitrariedades de toda clase en el sistema judicial, corrupción, interceptación de las llamadas telefónicas, eliminación del subsidio a los servicios públicos, paro del transporte público, epidemia de dengue hemorrágico, etc.- parece ser lo suficientemente perturbadora como para sacarla de su 
aparente inercia. Aunque, en algunas ocasiones, las decisiones del poder contrarias a los intereses populares provocan protestas violentas; pero éstas, por violentas que puedan llegar a ser, desaparecen con la misma rapidez con la que surgen y, por lo general, no consiguen sus propósitos.

No obstante las apariencias y la tradición, esta actitud de la sociedad salvadoreña puede ser vista como un mecanismo de autodefensa, que le habría permitido sobrevivir en situaciones adversas y ante las cuales se consideraba impotente. Desde esta perspectiva, la pasividad sería aparente y, en cualquier caso, momentánea. Puede ayudar a comprender esta reacción desconcertante, a primera vista, la que esta misma población adoptó durante la guerra civil. La mayor parte se opuso a ella y no apoyó voluntariamente a ninguno de los dos bandos enfrentados; pero tampoco manifestó en público su sentir y pensar por miedo a la represión, en un principio, de ambos lados, los cuales creían por igual que la solución del conflicto social era militar. La población soportó la guerra y sus consecuencias crueles con una fuerte dosis de estoicismo y aprendió a convivir y a sobrevivir con ella, mostrando bastante creatividad. No se levantó en armas, tal como el FMLN calculó erronéamente, al lanzar sus ofensivas "finales". En parte, no lo hizo porque no estaba convencida del triunfo militar de los rebeldes, ni tampoco de sus ideales revolucionarios, $y$, en parte, porque temía que una victoria de cualquiera de los dos ejércitos daría paso a una represión despiadada. Sin embargo, esto no significó que tomara partido por el lado gubernamental, sino que se esforzó por mantenerse a igual distancia de ambos ejércitos, aun cuando para ello tuviera que apoyar a uno u otro, en determinado momento.

La población salvadoreña no permaneció pasiva durante la guerra civil. Exceptuando el reducido grupo que optó por formar parte de uno u otro ejército, en respuesta a la presión ejercida por la militarización de la sociedad y a la vulnerabilidad en la cual ésta las mantenía, la mayor parte enfrentó el conflicto con una voluntad férrea, determinada a vivir. Esta determinación estimuló la creatividad para superar las dificultades generadas por las condiciones adversas de la guerra. En este sentido, la creatividad y la paciencia popular fueron recursos eficaces hasta cierto punto, claro está, contra la adversidad y la crueldad del conflicto armado. Asegurada la sobrevivencia, la población, silenciosa, pero de una manera tenaz, comenzó a buscar una salida fuera de El Salvador. Entonces, la corriente migratoria aumentó. Emigrar no fue sólo una solución individual, sino también familiar e incluso comunitaria, tal como lo pone de manifiesto la residencia de vecinos del mismo pueblo de origen en una misma área de Estados Unidos. Una vez que un miembro del grupo familiar o de la comunidad lograba establecerse en el extranjero, comenzaba a buscar la manera de llevarse a los demás, uno a uno, y éstos, a su vez, ya establecidos, hicieron lo mismo con otros. Resultado de este proceso es que los salvadoreños, en la actualidad, no viven de manera aislada, sino que, por lo general, conforman comunidades, que organizan actividades so- 
ciales, deportivas, culturales $y$ festivas - $e$ incluso económicas-, las cuales contribuyen a que no se sientan solos y aislados así como también a cultivar una nueva identidad. Los salvadoreños no ocultan su procedencia, ni su identidad, en el extranjero. Al contrario, se muestran orgullosos de ambas cosas, lo cual, por otro lado, molesta sobremanera al estadounidense promedio, quien tiende a considerarlos como intrusos, porque cree que sólo siendo estadounidense se puede ser verdaderamente ciudadano $e$ incluso ser humano.

Concluida la guerra civil sin que las condiciones

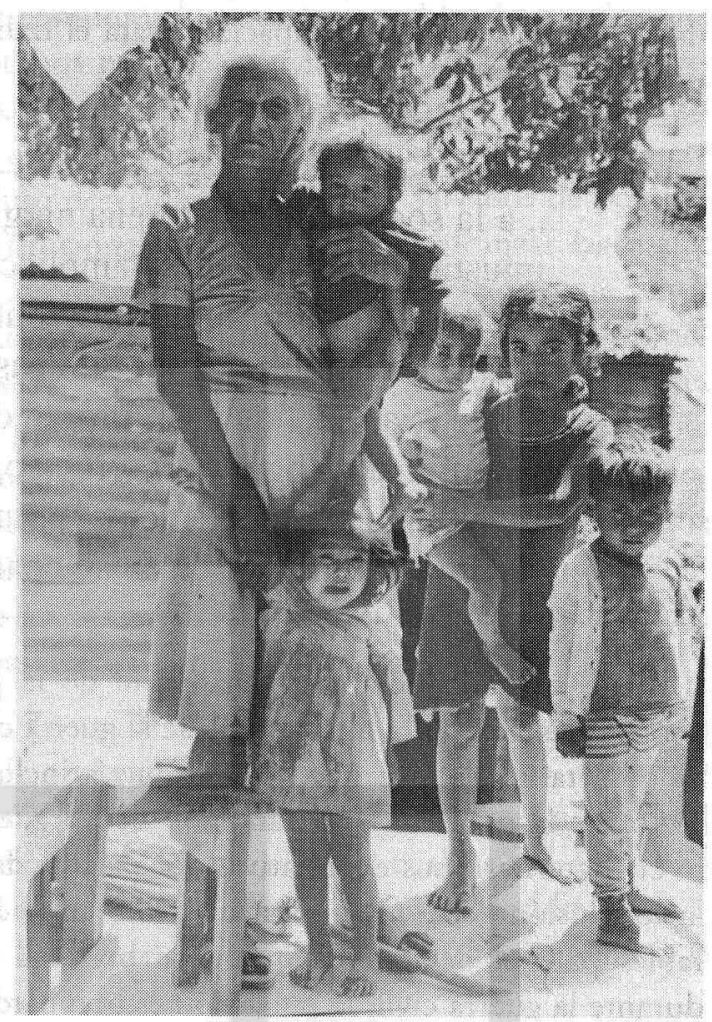
básicas de vida mejorasen de manera sustantiva, la reacción de la población salvadoreña sigue siendo la misma. Mientras sobrevive, busca la oportunidad para abandonar El Salvador y dirigirse á Estados Unidos, Canadá, Australia, Europa o México. La voluntad de vivir y la tenacidad - con frecuencia identificada con el ser salvadoreño y entendida, por lo general, como incansable para el trabajo- son las virtudes que le permiten enfrentar una situación como la actual, en la cual las libertades y los derechos fundamentales le están negadas y violados. Las remesas son a la vez un apoyo importante para sobrevivir y aguardar a que se presente la oportunidad que espera para emigrar, y un estímulo irresistible, porque serlan la constatación palpable del aprecio que se hace de su trabajo en el extranjero, donde éste es mejor retribuido que en El Salvador. Ahí, por el mismo esfuerzo percibe más dinero y dispone de más y mejores oportunidades para vivir. No son pocos los salvadoreños y las salvadoreñas que han encontrado en el extranjero las oportunidades que necesitaban para establecerse, superarse y prosperar, las cuales les son negadas en su propio país. No es nada fácil abrir un negocio o fundar una empresa en Estados Unidos o Canadá. Antes es necesario hacer trámites burocráticos de todo tipo, garantizar el pago exacto de los impuestos, aceptar controles de calidad estrictos y responsabilidad empresarial, etc., pero los salvadoreños pasan por todo ello y se apoderan de la oportunidad que se les presenta para desarrollar su creativi- 
dad y poner a prueba su capacidad para el trabajo. Esto es, precisamente, lo que El Salvador les niega.

... a la sociedad salvadoreña ninguna arbitrariedad, injusticia o escándalo - ampliación del impuesto al valor agregado, subida descontrolada del precio de los combustibles, escasez de gas y agua, descontrol de la violencia y del delito [...] paro del transporte público, epidemia de dengue hemorrágico, etc.- parece ser lo suficientemente perturbadora como para sacarla de su aparente inercia.

Si la reacción de una buena parte de la población salvadoreña no ha variado después de la finalización de la guerra civil es porque sus condiciones de vida tampoco han mejorado o quizás incluso han empeorado. Para este sector de la población, la transición de posguerra no ha traído nada nuevo, lo cual contraría sus expectativas por partida doble, porque no sólo esperaba la conclusión del conflicto armado, sino también unas condiciones más favorables para el desarrollo de la vida personal y comunitaria. Al igual que durante la guerra civil, la población es bombardeada con mensajes contradictorios. En aquel entonces estuvo sometida a la propaganda gubernamental y rebelde; en la actualidad, unos le aseguran que El Salvador es nuevo, que avanza hacia la prosperidad y le ofrece oportunidades, pero otros le hablan de arbitrariedad, corrupción y delincuencia. Al igual que entonces, recibe la información y la procesa de alguna manera; pero su reacción no es inmediata, ni visible. De ahí que sea erróneo atribuirla a falta de información. Al igual que en la década de los ochenta, esta población descontenta y desengańada no se levanta para protestar de manera masiva - exceptuando algunos brotes esporádicos y sin consecuencias mayores, probablemente porque sabe que sólo males le sobrevendrían de una movilización de esta clase. En lugar de ello, prefiere esperar la oportunidad para emigrar — una salida de mediano y largo plazo muy prometedora.

Mientras esa oportunidad se presenta, manifiesta su rechazo al orden establecido haciendo caso omiso de sus normas y reglas, contribuyendo con su conducta al desorden ya existente. Sin embargo, es curioso observar cómo ese mismo ciudadano que en El Salvador, su país de origen, no respeta las reglas y se muestra dispuesto a violar las leyes, según sus conveniencias, en los países a donde emigra y donde reside las observa rigurosamente. En parte, porque sabe que, con toda seguridad, será sancionado por las instituciones respectivas y porque, además, se arriesga a ser deportado; pero, en parte, porque sabe que sólo así puede conseguir la aprobación social de sus 
nuevos vecinos y de su nueva comunidad. Cuando la población no dispone de medios institucionales legítimos para alcanzar las metas sociales que considera valiosas, modifica su patrón de conducta para remover o superar los obstáculos que se interponen entre él y aquéllas. En estos casos, la conducta se vuelve innovadora -e incluso desviada. Como en El Salvador de posguerra no existen los medios institucionales adecuados para alcanzar las metas sociales más valoradas, no queda otra alternativa que innovar. En este sentido, la emigración y la conducta delictiva son innovaciones, aunque la primera se considera legítima si observa las leyes migratorias, mientras que la otra es una conducta desviada. La publicidad invita a consumir y la gente acepta sin mayor crítica esta invitación, pero pronto cae en la cuenta que no dispone de los medios para satisfacer sus aspiraciones consumistas. La clase media profesional es la que vive con mayor intensidad este desfase. En consecuencia, el orden establecido debe ser duramente criticado porque propone unas metas que son inalcanzables para la mayor parte de la sociedad.

Ahora bien, la emigración no es la única reacción de rechazo al orden establecido por la transición de posguerra. Mientras se presenta la oportunidad para emigrar, la población expresa su descontento vital al menos de otras tres maneras. Una de ellas es el ausentismo electoral, el cual ha ido creciendo a lo largo de la década de los noventa. Por eso, a la hora de decidir sobre si adoptar o no un documento único de identidad, los políticos dudan si la población acudirá a registrarse de forma voluntaria.

Otra manera es el fundamentalismo religioso, cuyo éxito entre las clases bajas y medias se explica porque, en sus asambleas y reuniones, enfatiza la efusividad emocional, en contraposición a las ceremonias distantes y frías de las iglesias; porque ofrece un padre que instruye a sus hijos e hijas con una mezcla de amor paternal y severidad, en contraposición a la predicación abstracta del clero de las iglesias establecidas; y porque exige a sus creyentes una obediencia fiel a reglas estrictas, la cual es reforzada por una carga ideológica intensa, cosas que las otras iglesias no exigen con la misma convicción. El fundamentalismo ofrece seguridades emocionales, prácticas e ideológicas contra la angustia, el abandono y la soledad; pero a costa de sacrificar deliberadamente el juicio crítico de la inteligencia. Ahora bien, el fundamentalismo no se limita a la esfera religiosa, sino que también predomina en la política económica y en su justificación. Sin embargo, la protección que pueda ofrecer es limitada y sólo es posible mantenerla con una enajenación cada vez mayor. Son frecuentes, sin embargo, las personas que no están dispuestas a ir tan lejos y lo acaban abandonando — tal vez porque ya han superado la crisis que las llevó a buscar refugio en esta peculiar forma de vida religiosa. El irinerario religioso comienza, por lo general, en el catolicismo, luego pasa por diferentes congregaciones y grupos para, al final, abandonarlos a todos y declararse sin religión o Iglesia. El fundamentalismo sólo puede sostenerse si conserva in- 
tactos sus mecanismos internos, evita el contraste con la realidad y renuncia a la racionalidad.

Existen, sin embargo, otras maneras más arriesgadas para sustituir la pérdida de seguridad emocional: el uso habitual de alcohol y drogas. Las personas emocionalmente aisladas beben, inhalan o se inyectan con regeularidad. El drogradicto arruinado y sin dinero, condenado de antemano a padecer una muerte sórdida, es un mito. Si no fuera así, si el grueso de la clientela fuera marginada, desempleada o delincuente de poca monta, el narcotráfico no tuviera la envergadura que tiene en la actualidad. Las sustancias psicotrópicas, al igual que el fundamentalismo, proporciona alivio (pasajero) a quienes experimentan deficiencias emocionales crónicas.

La vida en El Salvador se ha vuelto tan difícil que su población ha encontrado en la huida -física: la emigración; religiosa: el fundamentalismo; y evasiva: la adicción al alcohol y, o la droga - la única salida posible. La realidad salvadoreña se ha vuelto tan hostil y ofrece tan pocas posibilidades, que ya no es permisible vivir en su territorio. Dado que el impulso a la vida es más fuerte que cualquier otra atadura emocional a la tierra y, o a la familia que lo vio nacer y le ayudó a crecer, no queda otra salida que el desarraigo. Con la negación real y sistemática de la vida, se pierde la identidad fundamental. La huida es, por consiguiente, búsqueda de esa identidad perdida, en el extranjero, el fundamentalismo o la adicción. Quien huye no hace de su existencia una tragedia, pero tampoco está dispuesto a llevar una vida heroica. Unos tres millones de salvadoreños han optado por residir en América del Norte, Europa y Australia, y la cuarta parte de la población adulta que aún permanece en El Salvador también quisiera emigrar. El fundamentalismo y la adicción ofrecen una vía de escape para no pensar y flotar en el vacío. Esta movilización masiva hacia el extranjero, el fundamentalismo y la adicción dice mucho más sobre la clase de país que es El Salvador en la actualidad que las estadísticas. Es un país que obliga a sus habitantes ha abandonarlo.

Es cuestionable, entonces, que El Salvador pueda ser considerado como un país libre, puesto que impide a la mayoría de sus habitantes hacer y ser lo que ellos quisieran. Estos no cuentan con las posibilidades necesarias para optar por la vida que quisieran llevar. Tanto para los que se quedan como para los que se van, en El Salvador no existen condiciones reales para ejercitar las libertades que les permitan desarrollarse y crecer como personas, gozar de los derechos formales que esas libertades debieran garantizar y para crear. Hay que distinguir entre las libertades y los derechos de los cuales gozan unos cuantos, quienes sí cuentan con las condiciones para ello, y la negación positiva de las mismas para la inmensa mayor parte. En estas circunstancias es irreal, e incluso cínico, hablar de un El Salvador libre. Ofrecer igualdad de oportunidades, prescindiendo de la condición social y económica, no significa que esa igualdad esté a disposición de cualquiera. Las libertades y los 
derechos humanos, comenzando por el derecho a la vida, están, por lo pronto, si no negados de manera positiva a la mayoría de los salvadoreños, por lo menos restringidos.

El fracaso de las transformaciones impulsadas por una década de gobiernos de derecha en El Salvador está fuera de duda, si se parte del criterio de que la política estatal debe estar orientada a conseguir y garantizar el bienestar y la seguridad de la ciudadanía. La irreversibilidad de esas transformaciones es menos evidente y, por lo tanto, el retorno a un pasado que ahora, ante la anarquía actual, a algunos se les antoja como ideal, es, en la práctica, imposible. Aparte que nunca se puede retornar al pasado en cuanto tal. Por lo tanto, el esfuerzo por rescatar lo que, en sí mismo, no es rescatable, ya sea porque nunca existió tal como es imaginado, $y$, o porque el retorno a él es imposible. La huida hacia el futuro sirve poco, porque deja intacto el presente, en el cual, si no se introducen los cambios radicales necesarios, se prolongará sin alteración tal cual. Sin embargo, esto no significa que no haya salida, sino que cualquier salida que se intente debe partir de las transformaciones introducidas por la derecha y de la realidad a la cual ellas han dado paso. Desde esa realidad habrá que trabajar por su transformación.

La vida en El Salvador se ha vuelto tan difícil que su población ha encontrado en la huida -física: la emigración; religiosa: el fundamentalismo; y evasiva: la adicción al alcohol y, o la drogala única salida posible.

Un medio importante para conseguirla es la recuperación de la iniciativa comunitaria y social. Pero esta iniciativa sólo prospera cuando no es delegada en el Estado, ni en los partidos políticos, ni siquiera en las vanguardias, ni en los caudillos. Es así como las instancias sociales y comunitarias tendrían más vida y poder para decidir sobre aquello que las afecta; de esta manera se podrían superar, además, los dinamismos que hasta ahora han perturbado al poder político. El objetivo primordial de esta alternativa es la búsqueda del bien comunitario, desde la presión comunitaria y por medios comunitarios. Esta fuerza no puede ser delegada en instancias políticas, porque éstas se vuelven autónomas y nunca llegan a representar adecuadamente lo social. Esta experiencia de organización y fuerza comunitarias no es desconocida en El Salvador, pero su desarrollo es limitado y lento, por falta de convencimiento y oportunidades. Implícita a esta propuesta está la distinción entre la esfera pública y la estatal. En este sentido, no debe reservarse al Estado y a los partidos políticos todo el ámbito público, con menoscabo de las instancias sociales, pues, en el fondo, son formas de estatizar la vida social. 
Asimismo, debe evitarse el individualismo exacerbado, promovido por la forma como se ejerce el poder del Estado, en la actualidad. Lo social y lo comunitario deben ser entendidos como una mediación entre lo individual y lo político. I. Ellacuría nos recuerda que la dimensión comunal del individuo no se realiza primariamente en la dimensión política del Estado, sino en la dimensión pública de lo social. Esta dimensión es la que hay que conquistar junto con la dimensión comunitaria, la cual corre el peligro de quedar vinculada de una forma casi exclusiva a la seguridad y la policía. La descentralización del poder estatal es una posibilidad a duras penas explotada, no obstante ser una medida con un potencial incalculable para recuperar la dimensión de lo público, así como también su propia palabra. Con todo, siempre será necesario estar en guardia para no caer en la tentación de atribuirle o asumir un poder político estatal. Si este fuera el caso, desvirtuaría su función esencialmente social, puesto que recurriría a una mediación política para propugnar sus propios intereses, los cuales son de índole social. Cualquiera que sea la forma que esta conquista de la dimensión pública adopte, debe evitar la tentación de convertirse en apéndice del poder político, cualquiera que sea su ideología. De la misma manera, no debe olvidarse que es una dimensión que no le será regalada a la comunidad, sino que ésta deberá conquistarla. El poder político, que la monopoliza, no está dispuesto a entregarla de forma voluntaria por lo que eso implicaría de pérdida de poder o de democratización de la estructura social.

Ninguna de estas propuestas podrá mostrar su eficacia si, de alguna manera, no se está convencido de que la sociedad, en su conjunto, está viviendo muy por encima de sus posibilidades y, por lo tanto, para ser viable, deberá reducir su nivel de vida. Esto significa abandonar la idea de que el crecimiento económico es ilimitado y que una productividad creciente es la solución a los problemas sociales, y convertirse a un estilo de vida más modesto y austero, en beneficio de un reparto más equitativo de la riqueza nacional $-\mathrm{y}$ mundial- que es propiedad de todos y no privilegio de una reducida minoría. Es así como la civilización de la pobreza, fundamentada en el trabajo y la dignidad de la persona, propuesta por Ellacuría, se presenta de nuevo como una opción liberadora.

San Salvador, 21 de agosto de 2000. 